\title{
Editorial: Spelling Lesson
}

\author{
ANTONY FLEW \\ BEGRIFFSSCHRIFT \\ KIERKEGAARD \\ MORAVCSIK
}

\section{NICOMACHEAN ETHICS}

\section{NIETZSCHE}

\section{PEIRCE}

\section{SCHOPENHAUER}

\section{THEAETETUS}

